\title{
Advanced Powder Processing Techniques of Ti Alloy Powders for Medical and Aerospace Applications
}

\author{
Hideshi Miura* \\ Department of Mechanical Engineering, Kyushu University 744 Motooka, Nishi-ku, Fukuoka 819-0395, Japan
}

(Received October 8, 2013; Accepted October 10, 2013)

\begin{abstract}
In this paper, two kinds of advanced powder processing techniques Metal Injection Molding (MIM) and Direct Laser Forming (DLF) are introduced to fabricate complex shaped Ti alloy parts which are widely used for medical and aerospace applications. The MIM process is used to strengthen Ti-6Al-4V alloy compacts by addition of fine $\mathrm{Mo}, \mathrm{Fe}$ or $\mathrm{Cr}$ powders. Enhanced tensile strength of $1030 \mathrm{MPa}$ with $15.1 \%$ elongation was obtained by an addition of 4 mass $\% \mathrm{Cr}$ because of the microstructural modification and also the solution strengthening in beta phase. However, their fatigue strength was lower compared to wrought materials, but was improved by HIP. Subsequently, the effect of feeding layer height (FLH) on the characteristics of the DLF compacts was investigated. In the case of $100 \mu \mathrm{m} \mathrm{FLH,} \mathrm{sur-}$ face roughness was improved and nearly full density (99.8\%) was obtained. Also, tensile strength of $1080 \mathrm{MPa}$ was obtained, which is higher than the ASTM value.
\end{abstract}

Keywords: Metal injection molding, Direct laser forming, Ti alloys, Mechanical properties, Microstructure

\section{Introduction}

Advanced powder processing techniques such as metal injection molding (MIM) are hoped to be suitable for fabricating complex shaped Ti or its alloy parts with low cost. So far, we have applied MIM process to produce various types of Ti alloys using mixed powders such as Ti-6Al-4V [1], Ti-6Al-2Sn-4Zr-2Mo-0.1Si [2], Ti-6Al-2Sn-4Zr-6Mo [3], Ti-4.3Fe-7.1Cr [4], and Ti-6Al-7Nb alloys [5,6]. In this study, the MIM process has been applied to strengthen Ti$6 \mathrm{Al}-4 \mathrm{~V}$ alloy compacts by addition of fine Mo or $\mathrm{Fe}$ or $\mathrm{Cr}$ powders. These elements are beta stabilizing elements and have the potential to strengthen Ti-6Al-4V alloy effectively by solution strengthening [7] Also, they are more cost effective powders compared to Ti powder except for Mo powder. Furthermore they were sufficiently diffused in the sintered Ti compacts in previous studies $[3,4]$. To improve the mechanical properties of Ti-6Al-4V alloy compacts, the effect of powder type and sintering conditions on the relative density, mechanical properties and microstructures of the sintered compacts were mainly investigated.

On the other hand, direct laser forming (DLF) technique is another advanced powder processing technique [8]. In this process, powder material is embedded as a thin layer to be melted by laser scanning. Following this scanning, another powder layer is supplied and the same procedure is repeated, so that these solidified layers construct arbitrary shaped components. Recently, much effort has been made to apply this process to automobile, aerospace and medical fields due to the potential of producing complex shaped structures [9-12]. It has been reported that porous materials can be fabricated by this process in order to make artificial bone [13]. The artificial bone was made of a titanium alloy, Ti-6Al-7Nb, which does not contain any bio-toxic elements. In this study, we focused on metal powder feeding, especially feeding layer height (FLH). The reasons are: first, in the same laser scanning condition, the property of final product is strongly affected by the amount of melted metal pool as mainly determined by feeding layer height. Next, for industrial applications of DLF, we have to consider the processing time efficiency, which is dominantly decided by FLH. Therefore, this study presents the effect of FLH on the mechanical properties and surface roughness of laser formed metallic parts.

*Corresponding Author : Hideshi Miura, TEL: +81-92-802-3207, FAX: +82-92-802-3207, E-mail: miura@mech.kyushu-u.ac.jp 


\subsection{High Performance Ti-6Al-4V MIM Compacts} by Addition of Mo, $\mathrm{Fe}$ or $\mathrm{Cr}$

\subsubsection{Experimental Procedure}

Gas-atomized pure Ti powder (TILOP 45, Osaka Titanium technologies Co., Ltd), Al-40V powder (VAL-3, Nippon Denko Co., Ltd.), fine Mo powder (Mo-1KD, Japan New Metals Co., Ltd), fine Carbonyl Fe powder (Carbonyl FE MO, Fukuda Metal Foil \& Powder Co., Ltd.) and fine Cr powder (ELCREL-F4, F. W. Winter Inc. \& Co.) were used. The chemical compositions, particle size and scanning electron microscope (SEM) images of these powders are shown in Table 1 and Fig. 1, respectively. The amount of Mo or $\mathrm{Fe}$ or $\mathrm{Cr}$ added was decided from preliminary experiments, and the Molybdenum Equivalence [7] which gives the phase-stability classifications is determined by Eq. (1).

$$
\begin{gathered}
{[\mathrm{Mo}] \text { eq }=[\mathrm{Mo}]+[\mathrm{Ta}] / 5+[\mathrm{Nb}] / 3.6+[\mathrm{W}] / 2.5+[\mathrm{V}] / 1.5} \\
+1.25[\mathrm{Cr}]+1.25[\mathrm{Ni}]+1.7[\mathrm{Mn}]+1.7[\mathrm{Co}]+2.5[\mathrm{Fe}]
\end{gathered}
$$

The mechanical properties of Ti-6Al-4V alloy sintered compacts with added Mo or $\mathrm{Fe}$ or $\mathrm{Cr}$ powders had a tendency to decrease the elongation with increasing Mo or $\mathrm{Fe}$ or $\mathrm{Cr}$ contents. The Molybdenum Equivalence, by which the sintered compacts showed more than $10 \%$ of elongation, was around 7. Accordingly, the addition contents of $\mathrm{Mo}$ or $\mathrm{Fe}$ or $\mathrm{Cr}$ were determined as follows: 4 mass $\%$ of Mo ([Mo]eq=6.7), 2 mass $\%$ of Fe (7.7) and 4 mass $\%$ of $\mathrm{Cr}$ (7.7). These powders were pre-mixed for $3.6 \mathrm{ks}$ by pot mill rotator in argon atmosphere. The powder mixtures
Table 1. Chemical compositions and particle size of the powders used in this study

\begin{tabular}{lcccc}
\hline \hline Powder & $\begin{array}{c}\mathrm{O} \\
(\text { mass\%) }\end{array}$ & $\begin{array}{c}\mathrm{C} \\
(\text { mass\% })\end{array}$ & $\begin{array}{c}\mathrm{Fe} \\
(\text { mass\% })\end{array}$ & $\begin{array}{c}\text { Partile size } \\
(\mathrm{mm})\end{array}$ \\
\hline $\mathrm{Ti}$ & 0.13 & 0.008 & 0.044 & -45 \\
$\mathrm{Al}-40 \mathrm{~V}$ & 0.47 & 0.02 & 0.16 & -20 \\
$\mathrm{Mo}$ & 0.20 & --- & 0.008 & $1.59^{*}$ \\
$\mathrm{Fe}$ & 0.38 & 0.74 & val. & $4.31^{*}$ \\
$\mathrm{Cr}$ & 0.75 & 0.025 & 0.22 & $2.97^{*}$ \\
\hline
\end{tabular}

*Mean particle size

were then kneaded with a binder by means of a pressuretype kneading machine at $443 \mathrm{~K}$ for $8.1 \mathrm{ks}$. The powder loading was $65 \mathrm{vol} \%$ and the binder system was composed of polypropylene (30 mass\%), polymethyl methacrylate (40 mass\%), paraffin (29 mass\%) and stearic acid (1 mass\%). The compounds obtained were crashed and screened from $2 \mathrm{~mm}$ to $8 \mathrm{~mm}$ diameter for a injection molding feedstock. The feedstock was then injection molded into the tensile test specimens with a length of $75 \mathrm{~mm}$, a width of $5 \mathrm{~mm}$ and a thickness of $2 \mathrm{~mm}$. After injection molding, the extraction debinding with vaporized solvent, conducted at $343 \mathrm{~K}$ for $21.3 \mathrm{ks}$ in $\mathrm{n}$-hexane [8], was used to partially remove the wax and polymethyl methacrylate. Then, thermal debinding was performed from room temperature to $703 \mathrm{~K}$ in reduced pressure with an argon gas flow, and continuous sintering was performed in high vacuum $\left(<10^{-2}\right.$ $\mathrm{Pa})$ at various temperatures for $14.4 \mathrm{ks}$.

The density of sintered compacts was measured by the

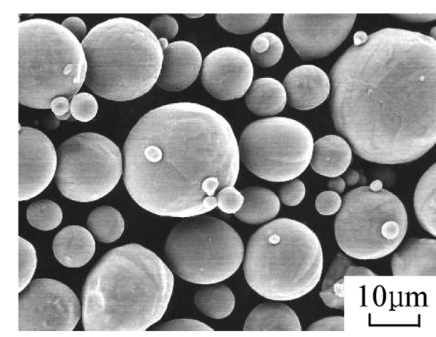

(a) Titanium powder

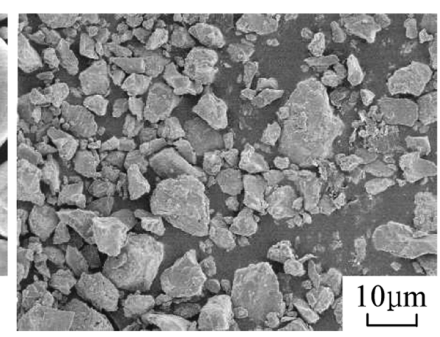

(b) Al-40V alloy powder

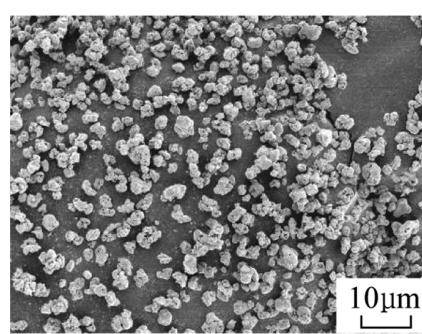

(c) Molybdenum powder

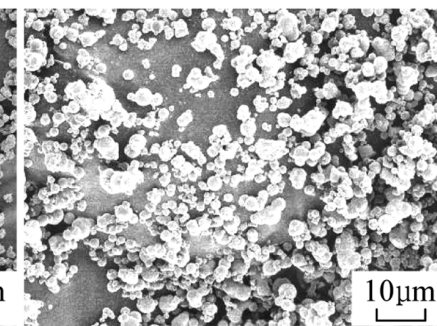

(d) Iron powder

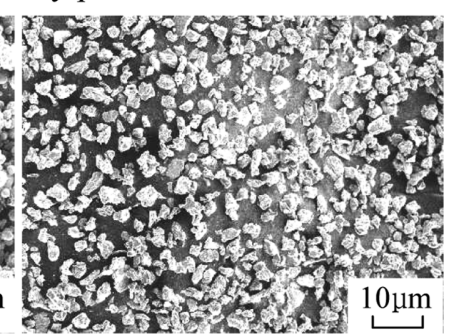

(e) Chromium powder

Fig. 1. SEM images of (a) Titanium, (b) Al-40V alloy, (c) Molybdenum, (d) Iron and (e) Chromium powders used in this study. 
Archimedean method with an automatic densimeter. The tensile test was conducted using a universal testing instrument and non-contact video extensometer with a crosshead speed of $8.33 \times 10^{-5} \mathrm{~m} / \mathrm{s}$ in air at room temperature. To determine the distribution of each element in the sintered compacts, characteristic X-ray images were taken using an electron probe micro analyzer with a wavelength dispersive analyzer. X-ray diffraction analysis was also performed to estimate the phase constitution of the sintered compacts using $\mathrm{Cu}-\mathrm{K} \alpha$ radiation.

\subsubsection{Result and Discussion}

Fig. 2 shows the effect of sintering temperature on the relative density of Ti-6Al-4V alloy compacts added with $\mathrm{Mo}$ or $\mathrm{Fe}$ or $\mathrm{Cr}$ powders. The relative density of the compacts increased with increasing sintering temperature and reached $99 \%$ at $1573 \mathrm{~K}$. As for the effects of $\mathrm{Mo}$ or $\mathrm{Fe}$ or $\mathrm{Cr}$ addition, the relative density of the compacts with added powder is about $1 \%$ higher than that of the compacts without additions. This seems to be due to the enhancement of densification by additional small particles of Mo or Fe or Cr. Fig. 3 and Fig. 4 show the tensile strength and elongation of Ti-6Al-4V alloy compacts with added $\mathrm{Mo}$ or $\mathrm{Fe}$ or $\mathrm{Cr}$ powders, respectively. The tensile strength of sintered compacts is significantly improved by additions with the effect of $\mathrm{Cr}$ addition for strengthening is larger than Mo or Fe addition. For example, the tensile strength of sintered compacts is increased by about $90 \mathrm{MPa}, 110 \mathrm{MPa}$ and 150 $\mathrm{MPa}$ by an addition of 4 mass $\%$ of Mo, 2 mass $\%$ of $\mathrm{Fe}$ and 4 mass $\%$ of $\mathrm{Cr}$ respectively, reaching $1030 \mathrm{MPa}$ by

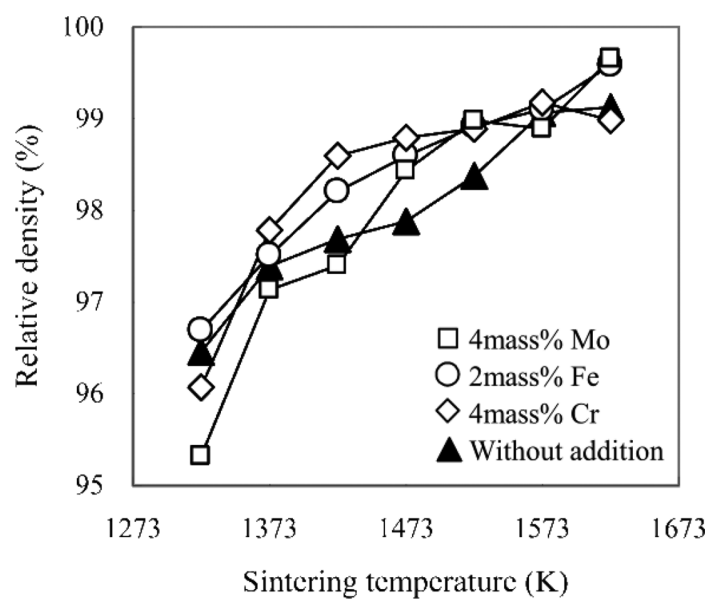

Fig. 2. Effect of sintering temperature on the relative density of Ti-6Al-4V alloy compacts with added Mo or $\mathrm{Fe}$ or $\mathrm{Cr}$ powders.

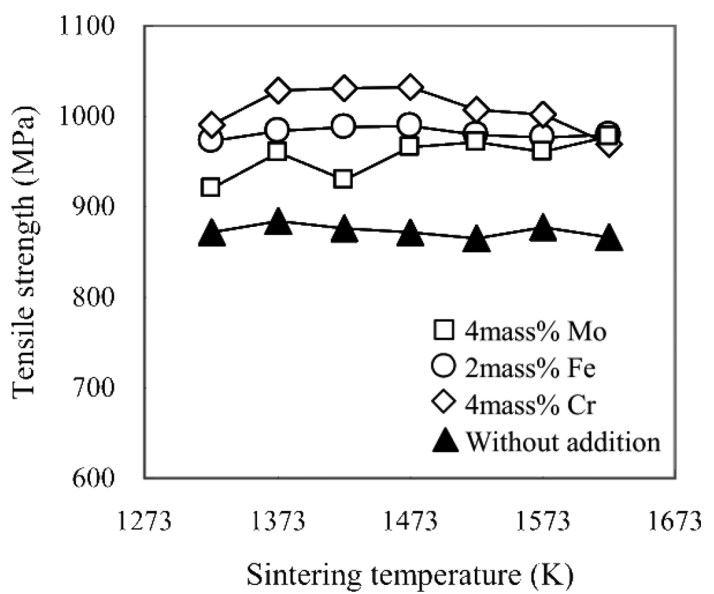

Fig. 3. Effect of sintering temperature on the tensile strength of Ti-6Al-4V alloy compacts with added Mo or $\mathrm{Fe}$ or $\mathrm{Cr}$ powders.

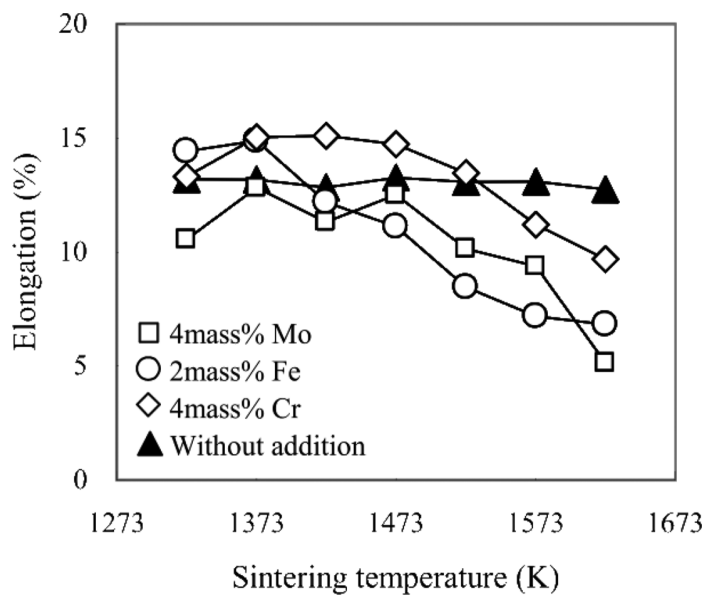

Fig. 4. Effect of sintering temperature on the elongation of Ti-6Al-4V alloy compacts with added Mo or Fe or Cr powders.

addition of 4 mass $\%$ of $\mathrm{Cr}$. On the other hand, the tensile strength of the compacts with additions of Mo and Fe are nearly constant with increasing sintering temperature. Compacts with added $\mathrm{Cr}$ shows a little increase at low sintering temperature, and then slightly decreased with increasing sintering temperature above $1473 \mathrm{~K}$. The effect of densification on the tensile strength of these sintered compacts was hardly available due to the high relative density over $97 \%$. Although the elongation of sintered compacts added with $\mathrm{Mo}$ or $\mathrm{Fe}$ or $\mathrm{Cr}$ powders decreased at high sintering temperatures. These sintered compacts showed excellent ductility (above 13\% of elongation) at low sintering temperature. In particular, the elongation of sintered compacts added with $\mathrm{Fe}$ or $\mathrm{Cr}$ powders achieved was around $15 \%$ at low sintering temperature.

The carbon content of all compacts is nearly constant around 0.3 mass $\%$ with increasing sintering temperature. 


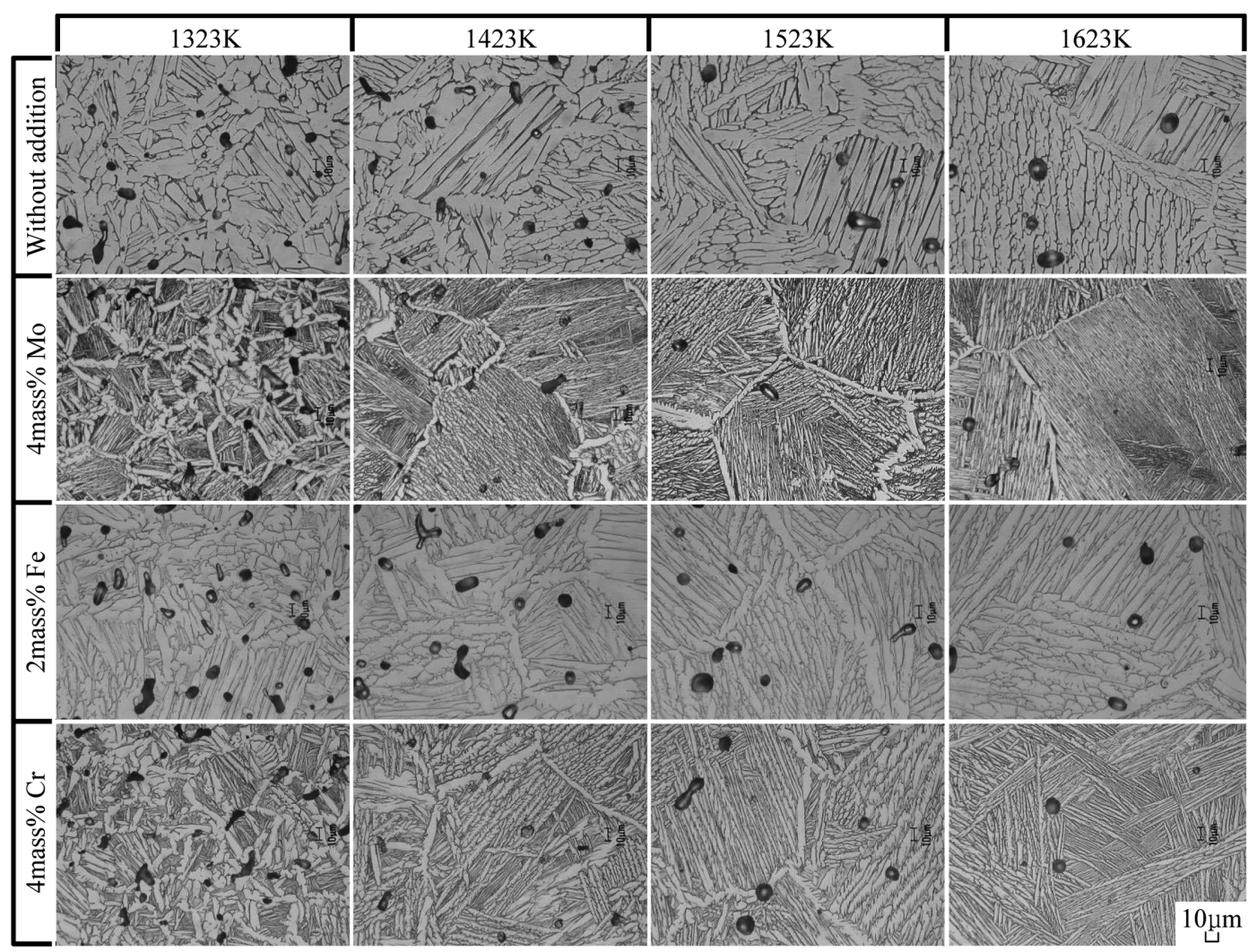

Fig. 5. Microstructures of Ti-6Al-4V alloy compacts sintered at various temperatures with addition of Mo or Fe or Cr powders.

Although the oxygen content of the sintered compacts slightly increased from 0.04 to 0.05 mass $\%$ by additions of Mo or $\mathrm{Fe}$ or $\mathrm{Cr}$ powders, these values are considered to be at low levels so that they have little detrimental effect on the mechanical properties of sintered compacts [14]. From these results, it was concluded that the addition of Mo or $\mathrm{Fe}$ or $\mathrm{Cr}$ has little influence on the oxygen and carbon contents of the sintered compacts.

Fig. 5 shows the microstructures of Ti-6Al-4V alloy compacts sintered at various temperatures with additions of $\mathrm{Mo}$ or $\mathrm{Fe}$ or $\mathrm{Cr}$ powders. The microstructures of all sintered compacts consist of acicular alpha phase and intergranular beta phase. The acicular alpha phase increases in length and becomes coarser with increasing sintering temperature. The lamellar like structure was caused by transformation from equiaxed beta grains during cooling. The grain size of prior beta increased with increasing sintering temperature and was over $50 \mu \mathrm{m}$ for the compacts sintered above 1423 $\mathrm{K}$. Although the addition of $\mathrm{Fe}$ has little influence on the microstructures of the sintered compacts, the addition of Mo or $\mathrm{Cr}$ has a fair influence on the microstructures, especially the acicular alpha phase becomes finer. From these observations, it is considered that the microstructural modification has

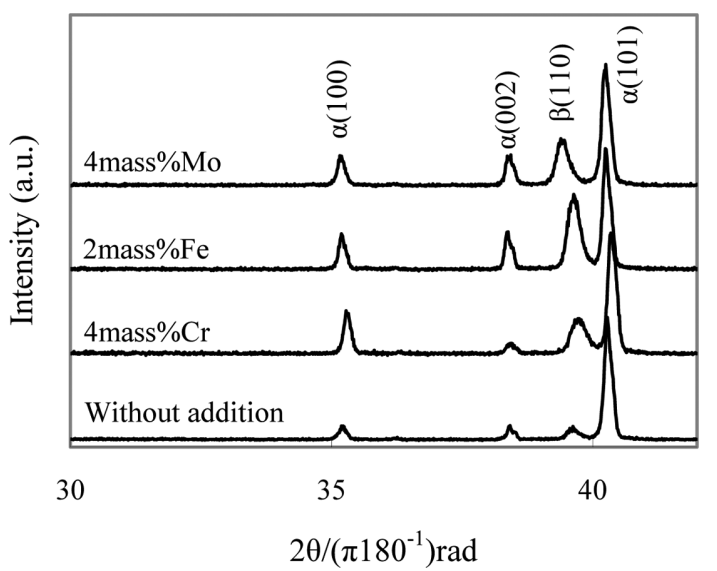

Fig. 6. X-ray diffraction profiles of Ti-6Al-4V alloy compacts sintered at $1423 \mathrm{~K}$ with addition of Mo or $\mathrm{Fe}$ or $\mathrm{Cr}$ powders.

an effect on the strengthening of the sintered compacts.

Fig. 6 shows the X-ray diffraction profiles of Ti-6Al-4V alloy compacts sintered at $1423 \mathrm{~K}$ with additions of Mo or $\mathrm{Fe}$ or $\mathrm{Cr}$ powders. These profiles were normalized by the intensity of the $\alpha$-Ti (101) diffraction profile. There are no profiles of intermetallic compounds such as $\mathrm{TiFe}$ or $\mathrm{TiCr}_{2}$, and both $\alpha$ and $\beta$ phases are detected in all sintered compacts. The intensity of $\beta$ (100) diffraction profile of the compacts with added Mo or Fe or Cr powders is higher than that of 


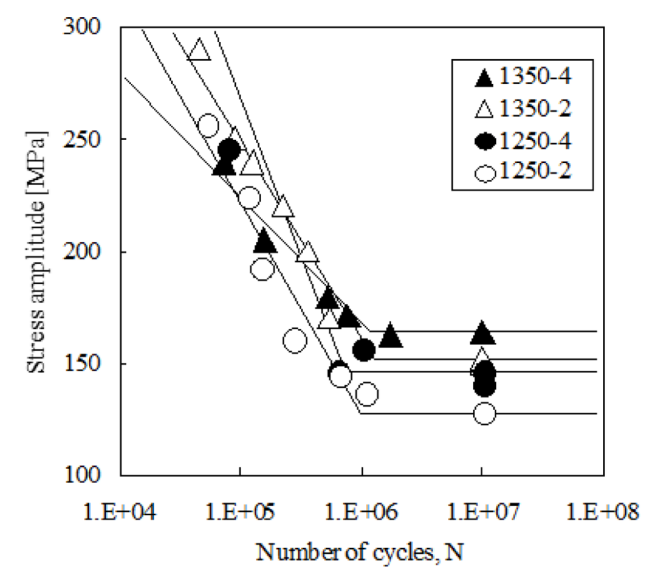

(a) $\mathrm{Ti}$

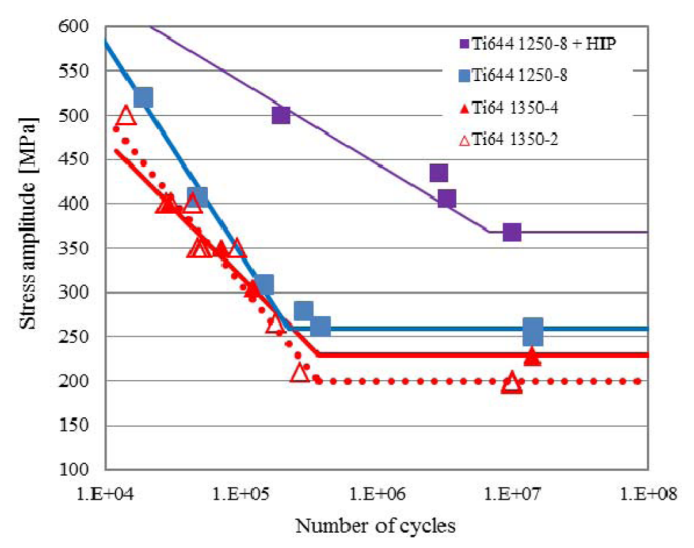

(b) Ti-6Al-4V, Ti-6Al-4V-4Cr

Fig. 7. S-N curves of injection molded compacts for (a)Ti and (b) Ti-6Al-4V, Ti-6Al-4V-4Cr.

the compacts without additions. This suggests that the volume fraction of $\beta$ phase is increased by additions of $\mathrm{Mo}$ or $\mathrm{Fe}$ or $\mathrm{Cr}$ powders. The diffraction angle of the $\beta$ (100) diffraction profile of the compacts with Mo powder is shifted to a lower angle and close to the theoretical value as compared with other compacts. This suggests that the lattice distortion in the beta phase of the sintered compacts with $\mathrm{Fe}$ or $\mathrm{Cr}$ powders is larger than the compacts with Mo powder. From these results, the strengthening of the sintered Ti-6Al-4V compacts with $\mathrm{Mo}$ or $\mathrm{Fe}$ or $\mathrm{Cr}$ powder addition was caused by not only the microstructural modifications but also solution strengthening in beta phase and increase of its volume fraction.

Fig. 7 shows the $\mathrm{S} / \mathrm{N}$ curves of bending fatigue test for Ti, Ti-6Al-4V and Ti-6Al-4V-4Cr sintered compacts. For Ti compacts, the fatigue endurance increases significantly with increase of sintering temperature and time. This seems to be due to the suppressed grain growth in spite of the increase of relative density, and low oxygen contents (less than 0.3 mass $\%$ ). Maximum fatigue endurance of $\mathrm{Ti}$ and Ti-6Al-4V compacts was $164 \mathrm{MPa}$ and $230 \mathrm{MPa}$, respectively. These values correspond to $70 \%, 45 \%$ of the ASTM standard value of wrought materials (Ti: $230 \mathrm{MPa}$, Ti-6Al-4V: $530 \mathrm{MPa}$ ). Ti-6Al-4V compacts shows lower ratio of fatigue endurance in comparison with $\mathrm{Ti}$ compacts because of remarkable grain growth. It could be also considered that the remaining large pores played the role of high sensitivity notch, which was confirmed in the fractured source. On the other hand, the results of Ti-6Al$4 \mathrm{~V}-4 \mathrm{Cr}$ were shown in Fig. 7(b). By the tensile test mentioned before, tensile strength was increased $160 \mathrm{MPa}$ by addition of $\mathrm{Cr}$. Fatigue endurance in this study also increased by 30 $\mathrm{MPa}$, which is not the same trend as the tensile strength. The reason of small improvement could be explained by the internal pores observed on the fractured surface of their compacts. Therefore, fatigue endurance is improved by HIP as shown in Fig. 7(b).

Fig. 8 shows the fractured surface of Ti, Ti-6Al-4V and Ti-

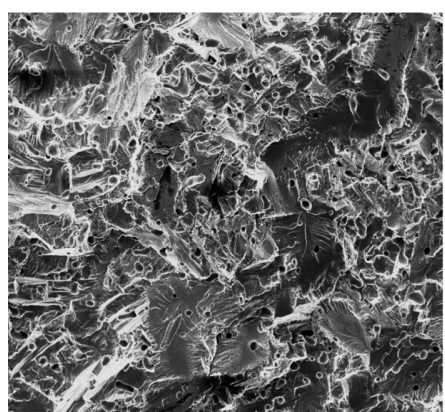

(a) $\mathrm{Ti}(170 \mathrm{MPa})$

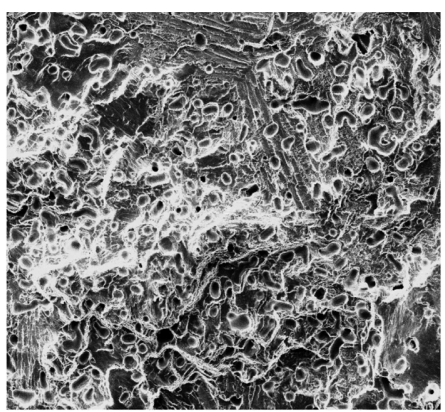

(b) Ti-6Al-4V (210MPa)

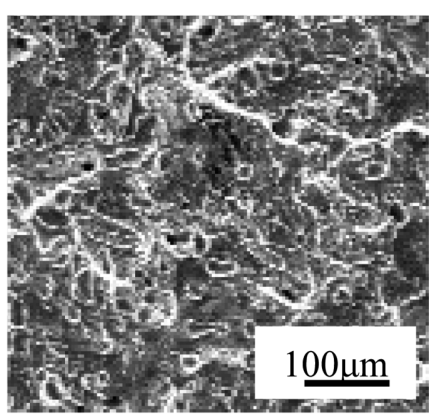

(c) Ti-6Al-4V-4Cr (280MPa)

Fig. 8. SEM images of fractured surface: (a) Ti, (b) Ti-6Al-4V, (c) Ti-6Al-4V-4Cr. 


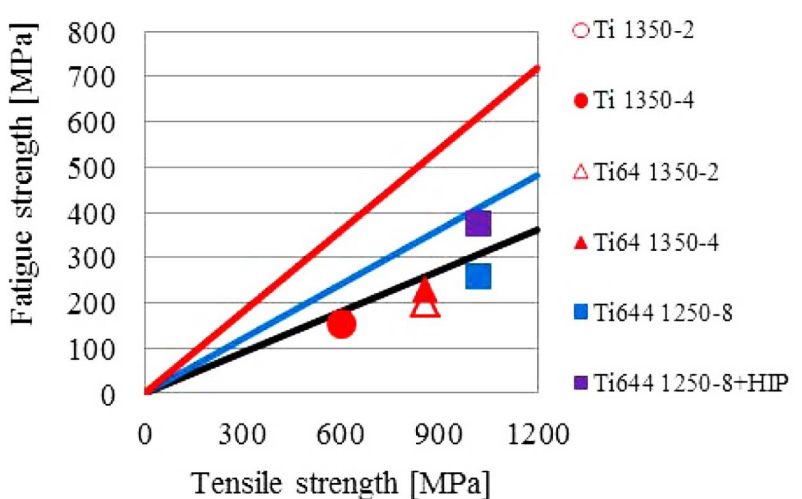

Fig. 9. Relationship between fatigue strength and tensile strength - Fatigue ratio.

$6 \mathrm{Al}-4 \mathrm{~V}-4 \mathrm{Cr}$ compacts. The dimple pattern indicating ductile fracture was observed in all compacts. The pore size of Ti$6 \mathrm{Al}-4 \mathrm{~V}$ and Ti-6Al-4V-4Cr compacts seems to be about twice the Ti compacts. As mentioned above, large size pores might play the role of internal notch, therefore Ti-6Al-4V compacts showed a lower ratio of fatigue endurance compared to wrought materials. Moreover, from the results of Ti-6Al-4V$4 \mathrm{Cr}$, remaining internal pores could be considered as the more dominant factor for fatigue endurance than additional elements and other parameters. Finally, it could be thought that the internal pores should be eliminated preferentially to improve the fatigue endurance of injection molded Ti alloy compacts.

Fatigue ratio is the relation between tensile strength and fatigue strength. The fatigue ratio of each material is shown in Fig. 9. The ratio of wrought metal is around 0.4-0.6 while that of $\mathrm{P} / \mathrm{M}$ material is usually around 0.3 [15]. From Fig. 9, the ratio of MIM compact shows around 0.3, even by HIP indicates 0.4 . This means that small notch such as pores may cause a decrease in fatigue strength.

\subsection{Improvement of Properties of Direct Laser Formed Ti-6Al-4V Compacts}

\subsubsection{Experimental Procedure}

A Ti-6Al-4V powder used in this study produced by a gas atomization process, is spherical with a particle size under $45 \mu \mathrm{m}$ (mean particle size: $34.4 \mu \mathrm{m}$ ) as shown in Fig. 10. All parts were made on a DLF machine developed in-house by our research group (Fig. 11). This DMLF installation is equipped with a ytterbium fiber laser (IPG YLR-300 SM), with a wavelength of $1070 \mathrm{~nm}$ and a maximum power of $300 \mathrm{~W}$ in continuous mode. For the laser used in this research, the spot diameter is about 50

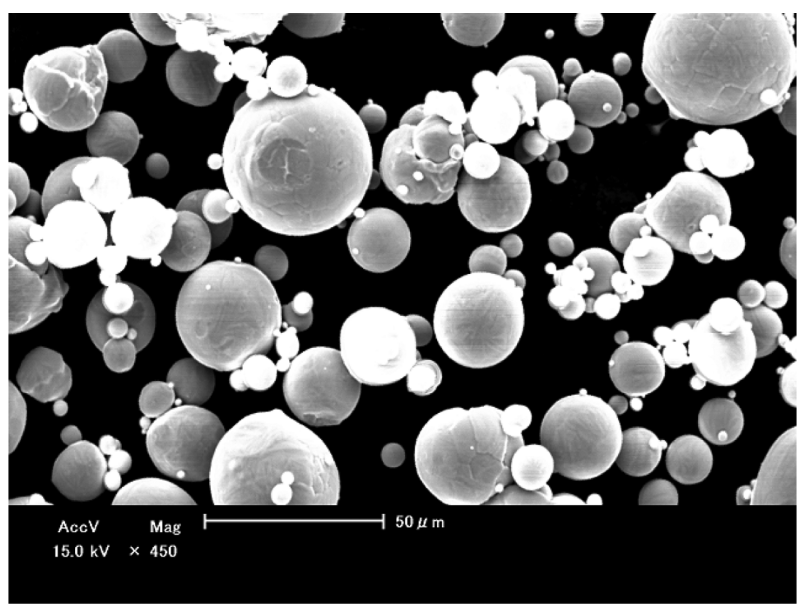

Fig. 10. SEM image of Ti-6Al-4V powder.

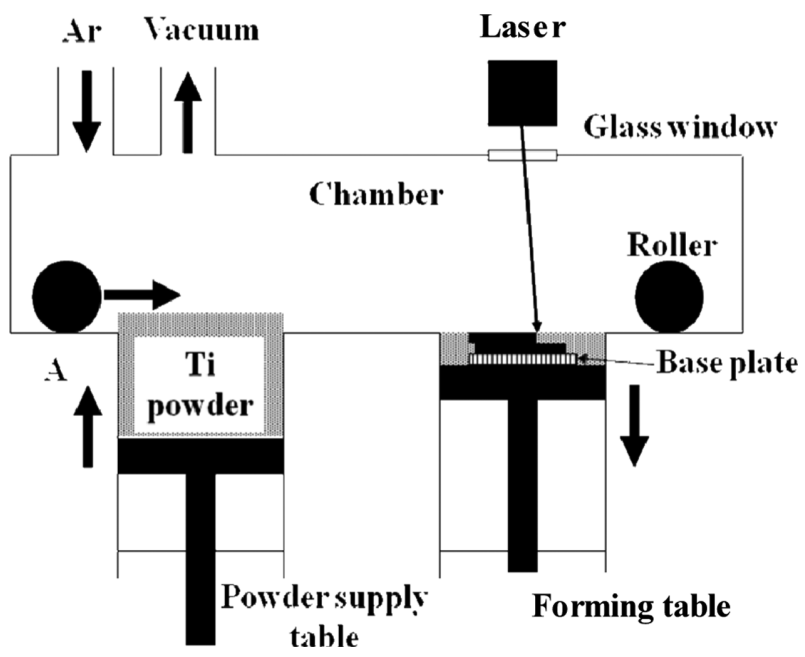

Fig. 11. Schematic of direct laser forming.

$\mu \mathrm{m}$. The forming chamber is first evacuated and then filled with an inert argon atmosphere to reduce the oxidation during laser forming. Parameters for processing of Ti-6Al-4V alloy in continuous laser mode are a laser power of $120 \mathrm{~W}$, a scanning velocity $v$ of $50 \mathrm{~mm} \mathrm{~s}^{-1}$ and a scan pitch $h$ of $200 \mu \mathrm{m}$. These conditions were optimized through preliminary experiments.

To investigate the influence of the feeding layer height on surface roughness and mechanical properties of laser formed bulk materials, single layer $(5 \times 5 \mathrm{~mm})$ specimens and multi-layer specimens (tensile specimens) was manufactured with different FLH. The tensile specimen has the dimensions shown in Fig. 12 (proportional shape of 14B type in JIS Z2201). Surface roughness of each specimen was measured with laser microscope (OLYMPUS, OL4000). Relative density of the tensile specimens was measured by image analyzer. Five cross-sectional pictures for each specimen 


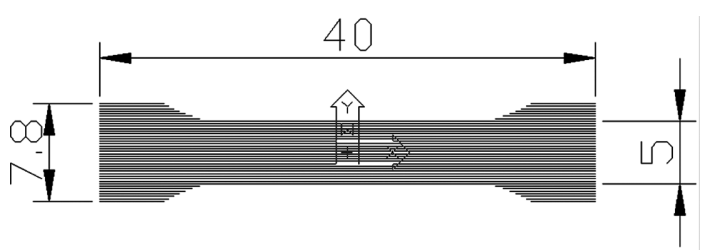

Fig. 12. 2D slice data of tensile specimen.

were used for image analyzing and the average was evaluated. The etched cross-section was observed in optical microscope. Oxygen content was estimated by oxygen analyzer (LECO TC-500SP). Vickers hardness and tensile strength were also assessed for each specimen.

\section{Results and Discussion}

The relationship between FLH and surface roughness is shown in Fig. 13. Surface roughness $\left(R_{z}\right)$ of single and multi-layer tends to improve with the decrease of FLH. In the case of a multi-layer, if the FLH is $150 \mu \mathrm{m}$ or more, surface roughness increases significantly and reaches a constant value of about $200 \mu \mathrm{m}$.

Fig. 14 shows the relative density of multi-layer specimens manufactured in different FLH. Almost full density $(99.8 \%)$ was obtained for small FLH $(100 \mu \mathrm{m})$, and for the others, about $85 \%$ of relative density was obtained. From this result, it is seen that high surface roughness results in low relative density. High FLH means that the amount of melted metal pool is larger, resulting in high surface roughness and low density through inhomogeneous melting and cooling. The effect of high surface roughness could be also confirmed in cross-sectional images in Fig. 15. Interestingly, if the FLH is high, inclined large pores form with uniform spacing. The forming mechanism of this unique pore structure will be briefly discussed in

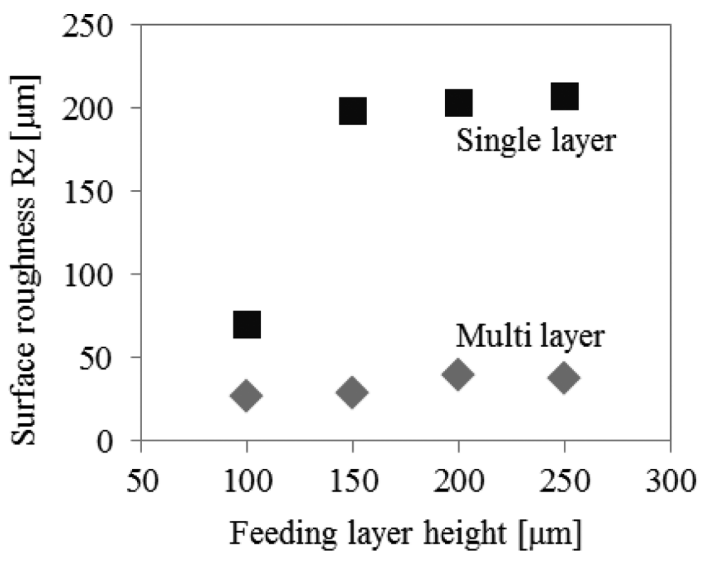

Fig. 13. Surface roughness of the single layer and multi-layer specimens.

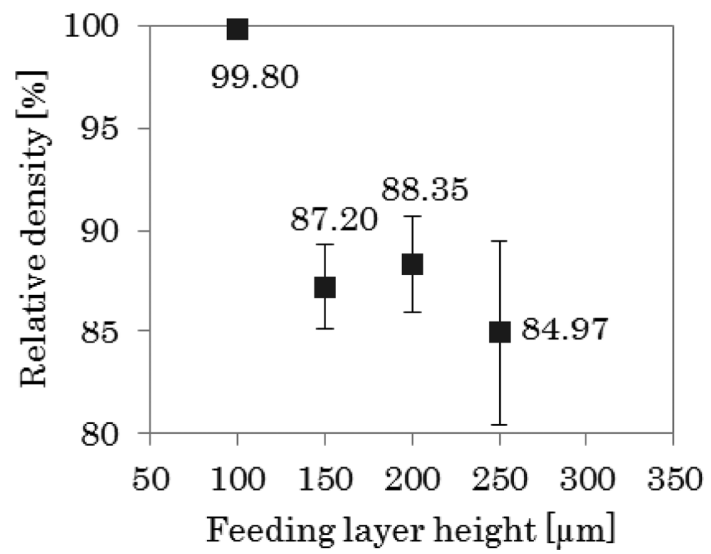

Fig. 14. Relative density of the tensile specimens with different feeding layer heights.

another section. It is thought that inhomogeneously melted metal pool makes these regularly arranged pores and large deviation in relative density; however it should be investigated in more detail.

In microstructure, an acicular martensitic phase due to rapid cooling and $\alpha+\beta$ phase were observed in all specimens (Fig. 16). In $100 \mu \mathrm{m}$ FLH, martensitic phase showed epitaxial
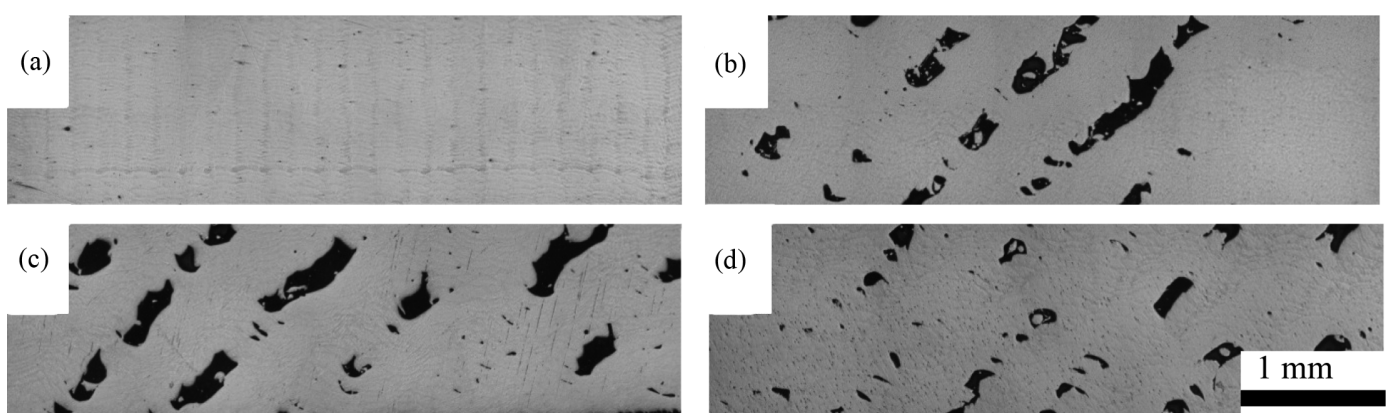

Fig. 15. Cross section of tensile specimens manufactured with different feeding layer height: (a) $100 \mu \mathrm{m}$, (b) $150 \mu \mathrm{m}$, (c) $200 \mu \mathrm{m}$, (d) $250 \mu \mathrm{m}$. 
growth in the same direction as the layering direction. Fig. 17 shows oxygen content of tensile specimens in different FLH. Oxygen content slightly increased compared to the raw material. However, this is not a concerning value for

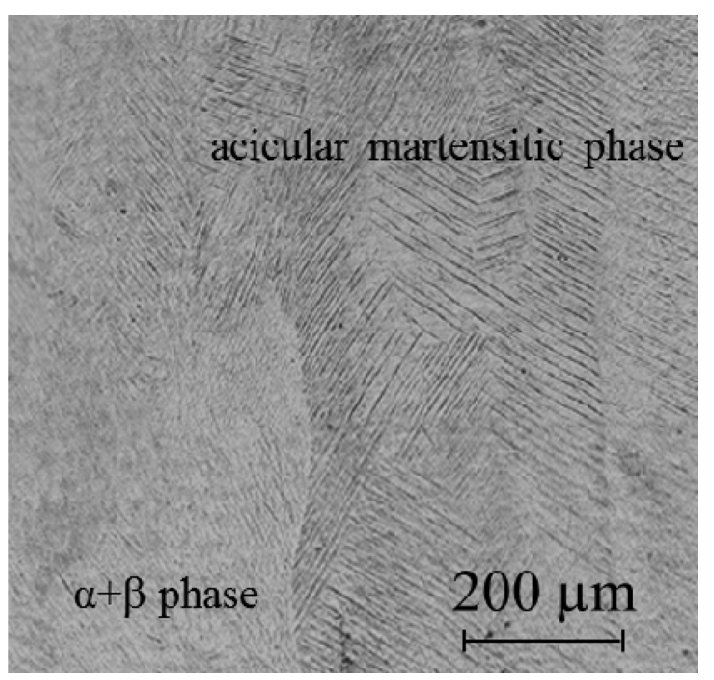

Fig. 16. Acicular martensitic phase with $100 \mu \mathrm{m}$ FLH specimen.

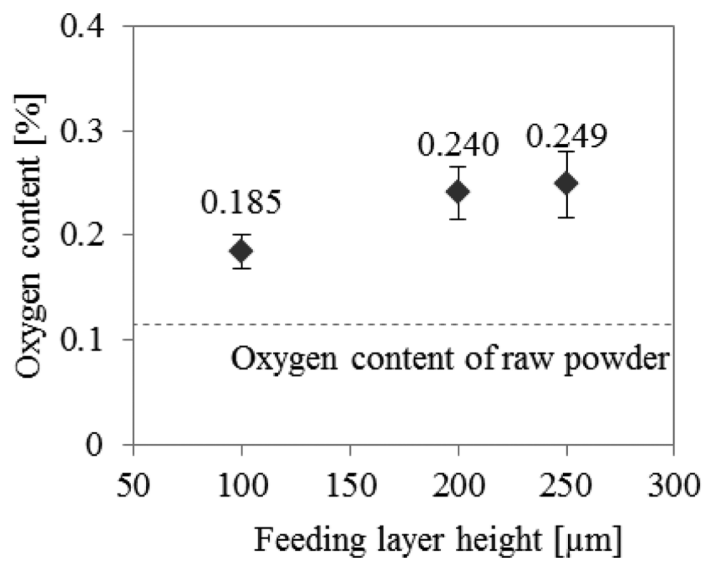

Fig. 17. Oxygen content of the specimens with different feeding layer height.

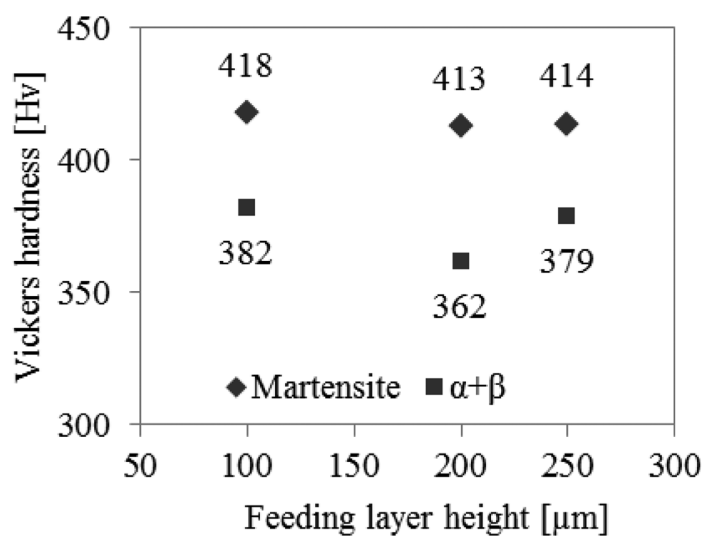

Fig. 18. Vickers hardness of the specimens with different feeding layer height. the decreasing of mechanical property.

Fig. 18 shows Vickers harness of each phase (martensite and $\alpha+\beta$ phase) of tensile specimens in different FLH. It is thought that Vickers hardness is not affected by FLH. The Martensitic phase showed about $410 \mathrm{Hv}$ and $\alpha+\beta$ phase showed about $370 \mathrm{Hv}$ in all FLH.

In Fig. 19, tensile strength in term of various FLH was shown. For $100 \mu \mathrm{m}$ FLH, a high tensile strength of 1083 $\mathrm{MPa}$, which is higher than the ASTM value was obtained due to high density and martensitic phase. For high FLH, in spite of low density and large inside pores, quite high tensile strength was obtained. However, in the case of high FLH, large deviation of tensile strength was observed due to the inhomogeneous relative density by high surface roughness. On the other hand, in small FLH, the consistency of the density was improved.

Fig. 20 shows the cross section of tensile specimen manufactured in $200 \mu \mathrm{m}$ FLH. The upper image is the surface layer showing a rough surface and the bottom image shows inside the specimen. The surface of specimen has a wave pattern formed by inhomogeneous melting and

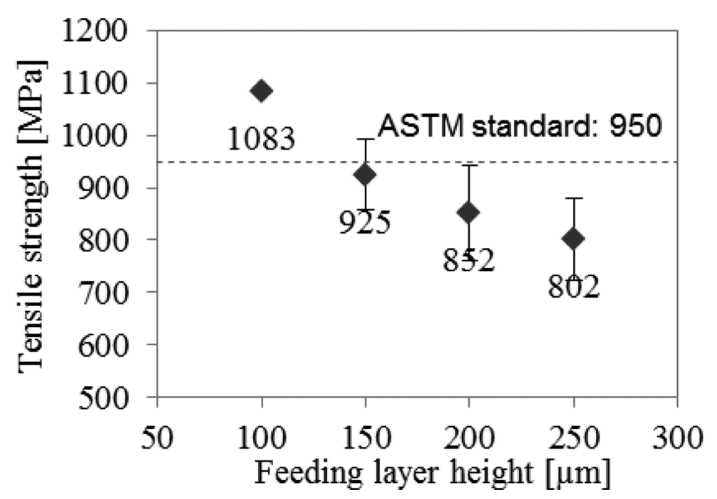

Fig. 19. Tensile strength of the specimens with different feeding layer height.

Surface layer of tensile specimen

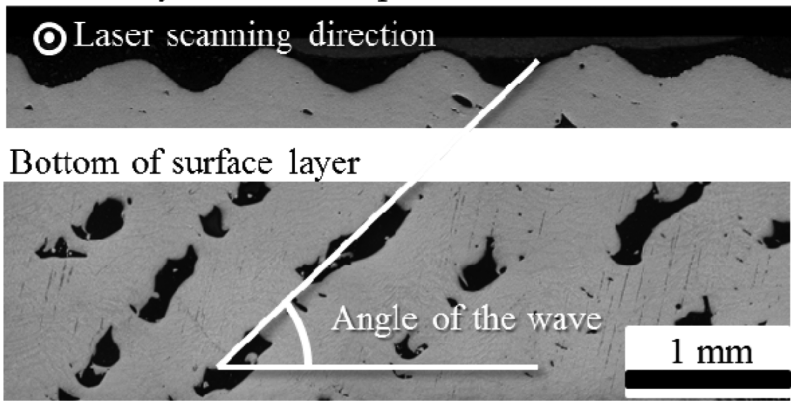

Fig. 20. Cross section of the tensile specimen manufactured with $200 \mu \mathrm{m}$ FLH; surface layer (upper) and bottom of the surface layer (bottom). 
solidification. The angle of the wave coincides with the angle of inside pore. This means that the bottom area of the wave remains a pore because the powder existing there is pulled into the melted pool and solidifies on the top of the wave. That is, high FLH causes an inhomogeneous surface having a wave pattern and this makes the unique pores structure inside the specimens. Therefore to control and improve the surface roughness and density, small FLH is strongly necessary.

\section{Conclusions}

The MIM process was applied to strengthen Ti-6Al-4V alloy compacts by an addition of fine $\mathrm{Mo}$ or $\mathrm{Fe}$ or $\mathrm{Cr}$ powders. The added Mo or $\mathrm{Fe}$ or $\mathrm{Cr}$ powders were sufficiently homogenized in all compacts even at low sintering temperatures, and the relative density of these compacts was above $97 \%$ due to the addition of small particles of $\mathrm{Al}-40 \mathrm{~V}, \mathrm{Mo}, \mathrm{Fe}$ and $\mathrm{Cr}$ powders. The strengthening of sintered Ti-6Al-4V alloy was caused by not only the microstructural modification but also the solution strengthening in the beta phase. Overall, the tensile strength of Ti-6Al$4 \mathrm{~V}$ alloy compacts was enhanced to $970 \mathrm{MPa}$ with $12.8 \%$ elongation by an addition of $4 \mathrm{mass} \% \mathrm{Mo}$, and enhanced to $980 \mathrm{MPa}$ with $14.8 \%$ elongation by an addition of 2 mass $\% \mathrm{Fe}$, and enhanced to $1030 \mathrm{MPa}$ with $15.1 \%$ elongation by an addition of 4 mass $\% \mathrm{Cr}$.

Small feeding layer height (FLH) is strongly effective for increasing density and mechanical property of DLF Ti6Al-4V compacts. Moreover, surface roughness could be improved by small FLH. In this study, $70 \mu \mathrm{m}$ in $\mathrm{R}_{z}$, $99.8 \%$ in density and $1080 \mathrm{MPa}$ in tensile strength were obtained by introducing a small feeding layer height. It might be thought that small FLH is a time-consuming process, however, extremely small feeding layer height (e.g.: single uniform particle height) should insure ultraresolution products by laser forming technique.

\section{Acknowledgement}

The author is most grateful to Mr. Nobuhiro Arimoto, Osaka Ti Technologies Co., Ltd., for providing the powders,
Dr. Yoshinori Itoh, Hamamatsu Technical support Center, industrial Research Institute of Shizuoka Prefecture, and Dr. Hyungoo Kang, Dr. Tsumori Fujio and Dr. Toshiko Osada, Kyushu University for their kind cooperation in the experiment.

\section{References}

[1] Y. Itoh, T. Harikou, K. Sato and H. Miura: 2004 Powder Metallurgy World Congress, 4 (2004) 445.

[2] Y. Itoh, T. Harikou, K. Sato and H. Miura: Journal of the Japan Society of Powder and Powder Metallurgy, 52 (2005) 43.

[3] Y. Itoh, T. Uematsu, K. Sato, H. Miura and M. Niinomi: Journal of the Japan Society of Powder and Powder Metallurgy, 55 (2008) 720.

[4] Y. Itoh, T. Uematsu, K. Sato, H. Miura, M. Niinomi and M. Ikeda: Journal of the Japan Society of Powder and Powder Metallurgy, 53 (2006) 821.

[5] Y. Itoh, H. Miura, T. Uematsu, K. Sato, M. Niinomi and T. Ozawa: Ti-2007 Science and Technology, The Japan Institute of Metals, 2 (2007) 1185.

[6] Y. Itoh, T. Uematsu, K. Sato, H. Miura and M. Niinomi: Journal of the Japan Society of Powder and Powder Metallurgy, 53 (2006) 750.

[7] R. Boyer, G. Welsch and E. W. Collings: Materials Properties Handbook: Titanium Alloys, ASM International (1994) 10.

[8] C. K. Chua, K. F. Leong and C. S. Lim: Rapid Prototyping: Principles and Applications 2nd ed., World Scientific Publishing, Singapore, (2003).

[9] H. Miura, H. Maeda, M. Uemura, T. Takemasu and M. Otsu: Mater. Sci. Forum, 534-536 (2007) 465.

[10] H. G. Kang and H. Miura: Adv. Mater. Res., 89-91 (2010) 281.

[11] H. G. Kang, T. Ishi, F. Tsumori and H. Miura: Journal of the Japan Society of Powder and Powder Metallurgy, $\mathbf{5 8}$ (2011) 436.

[12] H. Miura, K. Okawachi, H.-G. Kang, F. Tsumori, K. Kurata and N. Arimoto: Mater. Sci. Forum, 654-656 (2010) 2057.

[13] H. Miura, K. Okawachi, H. G. Kang, M. Uemura, M. Fujita and N. Arimoto: Proc. Powder Metallurgy \& Particulate Materials (2009), CD-ROM.

[14] Y. Itoh, T. Uematsu, K. Sato and H. Miura: Journal of the Japan Society of Powder and Powder Metallurgy, 56 (2009) 259.

[15] M. Hasegawa: Stainless steel Handbook, Nikkan Kogyo Shimbun, Ltd., (1973). 